\title{
MAPEAMENTO PARTICIPATIVO APLICADO AO ESTUDO DE RISCOS AMBIENTAIS NO BAIRRO RURAL SÍTIO NOVO, SÃO JOSÉ DO RIO PARDO/SP
}

\author{
Jeovanes Lisboa da Silva Filho ${ }^{1}$ \\ Amanda Cristina Alves Silva ${ }^{2}$ \\ Salvador Carpi Junior ${ }^{3}$
}

\begin{abstract}
RESUMO
O referido artigo é resultado do trabalho desenvolvido na área rural do município de São José do Rio Pardo/SP, onde se utiliza o mapeamento participativo como um instrumento de participação social da população que reside na área estudada atentando-se principalmente aos aspectos de ordem ambiental e vulnerabilidade social. Esse trabalho tem como objetivo levantar informações, dados e características relacionadas à experiência da população que reside no bairro rural Sítio Novo de forma qualitativa e quantitativa, através da percepção das pessoas que participam da reunião pública, que possibilita e estimula a discussão e posicionamento diante da realidade no campo da pesquisa. Os procedimentos metodológicos seguem os mesmos padrões adotados em trabalhos desse cunho que vem sendo desenvolvidos no Estado de São Paulo nas duas últimas décadas. Como resultado do método aplicado, são obtidos mapas com a participação de atores locais, através de aspectos negativos e também as potencialidades no meio em que se vive. É importante salientar que é necessário a intervenção, conferindo dados e informações que serão úteis ainda para embasar as decisões e ações do poder executivo municipal, colaborando até com o mesmo em sua gestão municipal. Sendo assim, espera-se que a sensibilidade, a subjetividade despertada ao longo do tempo de trabalho junto com a população participante contribua para amadurecimentos e maior responsabilidade nas tomadas de decisão do poder executivo, em relação aos aspectos ambientais do lugar, e que possa contribuir para a melhoria da qualidade de vida daqueles que ali vivem.
\end{abstract}

PALAVRAS-CHAVE: Mapeamento Participativo. Ricos Ambientais. Análise Ambiental.

\footnotetext{
${ }^{1}$ Graduando do curso de Licenciatura em Geografia pela Universidade de Pernambuco - Campus Garanhuns e bolsista IC CNPq. E-mail: jeovanelisboa@hotmail.com

${ }^{2}$ Mestranda em Geografia pela Universidade Estadual Paulista Campus Rio Claro e-mail: amandacristinaas@hotmail.com

${ }^{3}$ Doutor em Geociências e pequisador na Universidade Estadual de Campinas, Instituto de Geociências, Campinas-SP e-mail: salvador@ige.unicamp.br
} 
da Alta Paulista

\title{
PARTICIPATORY MAPPING APPLIED TO STUDY OF ENVIRONMENTAL RISKS IN RURAL NEW NEIGHBORHOOD SITE , SÃO JOSÉ DO RIO PARDO / SP
}

\begin{abstract}
This article is a work developed in the rural area of São José do Rio Pardo, São Paulo State, Brazil, which uses participatory mapping as a tool of social participation of local population, paying attention mainly to aspects of environmental and social vulnerability. This paper aims to gather information, data and characteristics related to experience of people living at Sítio Novo rural district qualitatively and quantitatively, through the perception of people who participate in the public meeting, that enables and stimulates discussion and positioning before the reality in the field of research. The methodological procedures follow the same standards adopted in work of this nature that has been developed at São Paulo State in the last two decades. As a result of the method applied, maps are obtained with the participation of local agents, through negative aspects and also the potential in the environment where they live. Importantly, the intervention is necessary, giving data and information that will be useful also to support the decisions and actions of the municipal executive. Thus, it's expected that the sensitivity, the subjectivity awakened during working hours with the participant population contributes to growth in maturity and accountability in decision-making of the executive power, on the environmental aspects of the place and can contribute to improving the quality of life of those who live there.
\end{abstract}

Keywords: Participatory mapping. Environmental risks. Social participation.

\section{MAPEO PARTICIPATIVO APLICADA AL ESTUDIO DE RIESGOS AMBIENTALES EN RURAL NUEVO SITIO BARRIO, SÃO JOSÉ DO RIO PARDO / SP}

\section{RESUMEN}

El artículo es el trabajo desarrollado en la zona rural del municipio de São José do Rio Pardo / SP, que utiliza la cartografía participativa como herramienta de participación social de la población que vive en el área de estudio está pagando principalmente atención a los aspectos relacionados con el medio ambiente y la vulnerabilidad social. Este trabajo tiene como objetivo recopilar información, datos y características relacionadas con la experiencia de las personas que viven en el barrio rural de Nuevo Sitio cualitativa y cuantitativamente, a través de la percepción de las personas que participan en la reunión pública, que permite y estimula la discusión y el posicionamiento en la realidad en el campo de la investigación. Los procedimientos metodológicos siguen las mismas normas adoptadas en el trabajo de esta naturaleza que se ha desarrollado en el Estado de São Paulo, en las últimas dos décadas. Como resultado del método utilizado, se obtienen mapas con la participación de los actores locales en los aspectos negativos y también el potencial en el medio ambiente en el que vivimos. Es importante destacar que la intervención es necesario, el suministro de datos e información que será útil también para apoyar las decisiones y acciones del ejecutivo municipal, trabajando incluso con el mismo en su gestión municipal. Por lo tanto, se espera que la sensibilidad, la subjetividad despertó con el tiempo de trabajo, junto con el participante población contribuye al crecimiento en la madurez y la responsabilidad en el poder de decisión ejecutiva en relación con los aspectos ambientales del lugar, y que puede contribuir para mejorar la calidad de vida de los que viven allí.

PALABRAS CLAVE: Mapeo Participativo. Rich Ambiental. Análisis Ambiental. 


\section{INTRODUÇÃO}

Diversas iniciativas buscam compreender e levantar dados de acordo com a percepção da sociedade que ali vive, e assim fornecer informações para a criação de estratégias para reverter e/ou amenizar problemas relacionados a situações de risco ambiental, em especial na área rural, onde os órgãos municipais raramente apresentam ações efetivas para melhoria da condição de vida no campo.

No pertinente trabalho reconhece-se que o mapeamento participativo é eficaz quanto à cognoscibilidade do lugar a ser estudado, pois é quem vive nele que é capaz de melhor apontar os problemas ambientais em suas diferentes interfaces.

As variedades de interpretações dos riscos por parte da sociedade juntamente com a experiência da realidade assistida cotidianamente permitem uma melhor visualização e compreensão de detalhes que aqueles que não vivem e não tem nele o sentimento de pertencimento não são capazes de verificar.

Este trabalho compõe o rol de ações realizadas no Estado de São Paulo de mapeamento participativo de riscos ambientais, efetuado então no município de São José do Rio Pardo, que permite conhecer a realidade e anseios dos moradores da área rural do bairro Sítio Novo, tornando-se assim instrumento de conhecimento e pauta para ações do poder executivo.

O município de São José do Rio Pardo encontra-se inserido na região Nordeste do estado de São Paulo, conforme consta na figura 1. Segundo o IBGE (2010) apresenta população de aproximadamente 51.900 habitantes, sendo que deste número, apenas 5.941 pessoas vivem zona rural, o restante, 45.959, situamse na área urbana, onde pode ser observado um grande adensamento populacional. Sua extensão territorial é de 419,186 km². 
Figura 1: Mapa de localização do município do São José do Rio Pardo/SP.

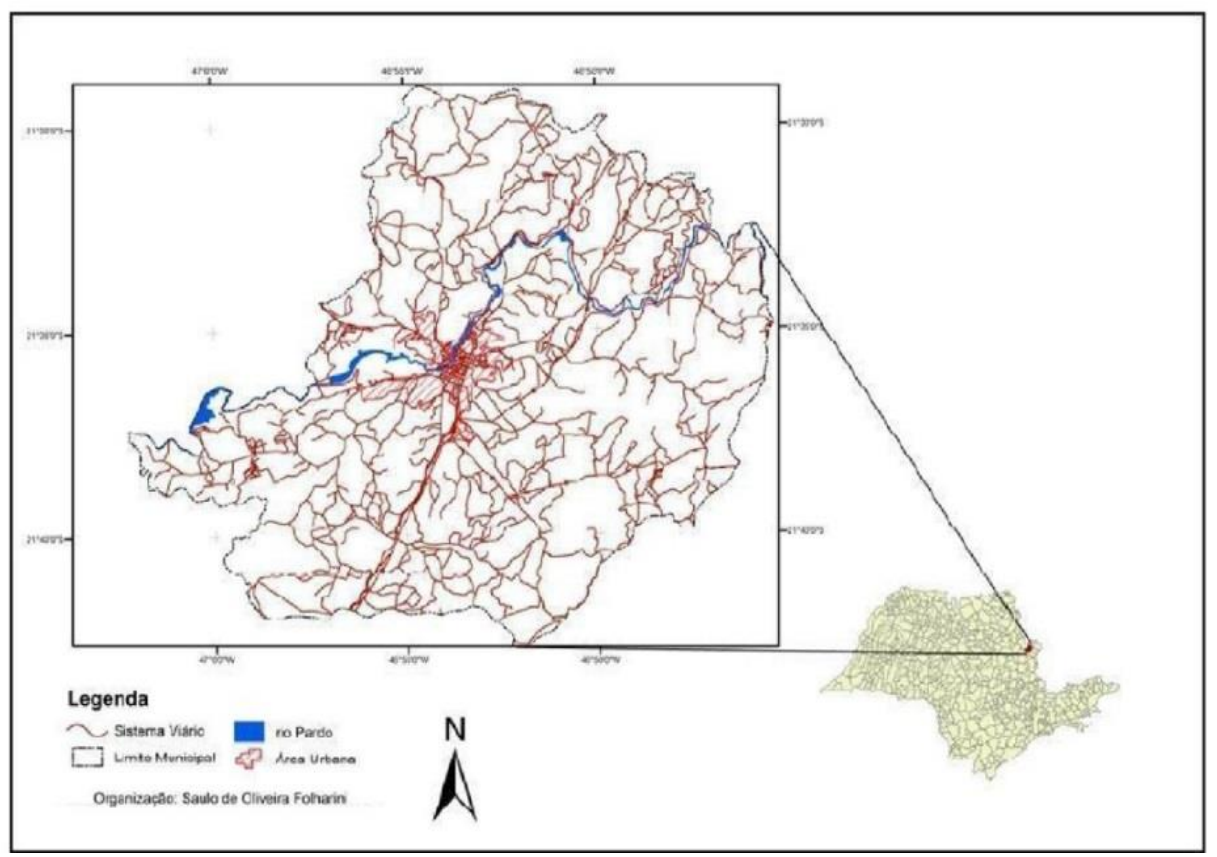

Fonte: FOLHARINI, 2012.

\section{MÉTODOS E TÉCNICAS}

Todos os elementos apresentados nos procedimentos técnicos e metodológicos, baseiam-se em trabalhos que utilizam o mapeamento participativo de riscos ambientais enquanto ferramenta de valorização da percepção dos participantes, nesse contexto tem-se que o mapeamento participativo apresenta a seguinte proposta:

Essa proposta de mapeamento remete à relevância de utilizar cientificamente, via análise qualitativa, a percepção e o conhecimento da população envolvida cotidianamente com os riscos ambientais. Essa proposta busca fornecer subsídios para que as comunidades afetadas obtenham maior eficácia na argumentação e no encaminhamento de melhorias, de medidas corretivas e de soluções estruturais (DAGNINO, 2007, p. 52).

Nessa perspectiva, Carpi Jr. (2011 p.10) ainda destaca que "uma das formas de mapeamento ambiental participativo com amplas possibilidades de aplicação é aquela que leva em conta a percepção ou o conhecimento da população afetada 
pelos riscos ambientais".

Sendo assim a população participa ativamente podendo colaborar com relados de suas experiências com o lugar para que possam apontar algumas potencialidades na sua comunidade e destacar também os principais problemas por eles enfrentados, sobretudo os ambientais, valorizando assim a sua percepção.

Porém, importa ainda ressaltar a importância da percepção, uma vez que a perspectiva da pesquisa é a valorização da mesma através da reunião pública, entendendo-se por percepção:

A percepção é tanto a resposta aos estímulos externos, como a atividade proposital, na qual certos fenômenos são claramente registrados enquanto outros retrocedem para a sombra ou são bloqueados. Muito que recebemos tem valor para nós, para a sobrevivência biológica e para propiciar algumas satisfações que estão enraizadas na cultura. (TUAN, 1980, p. 04).

Tuan, (1980), traz à tona o conceito de percepção em sua obra Topofilia, ou seja, na percepção é onde o sujeito externa o seu ponto de vista, ou seja, levar em consideração a percepção é valorizar a cultura, a história, formação, ou quaisquer outros aspectos da população participante.

Ainda atentando-se para o mapeamento participativo, Carpi Jr. e Perez Filho (2003) os mesmos destacam que "não se trata de substituir binariamente essa forma de produzir ciência por uma outra, "mais moderna", ou "menos tecnicista". O que se pretende é adicionar e integrar as percepções, os mapas mentais e a memória coletiva junto aos métodos já amplamente utilizados nas pesquisas geográficas e ambientais". Sabe-se ainda da relevância dos estudos do professor Seva Filho nos trabalhos de mapeamento participativo, onde o mesmo destaca a relevância desse método, afirmando que:

A relevância de um mapeamento de riscos ambientais está em conseguir-se elaborar um produto de aplicação didática para usar na formação de outras lideranças, e na educação popular. Algo em que os cidadãos se apoiem para o entendimento da própria região e de alguns dos seus próprios problemas. (SEVÁ FILHO, 1997, p. 1).

Ainda, dentro dessa ótica conceitual em que se encontra o termo, mapeamento participativo na proposição de Dagnino e Carpi Jr (2014), "o 
Mapeamento Ambiental Participativo tem alcançado excelentes resultados em pesquisas realizadas e adaptadas desde os anos 1990 em diversas áreas do Estado de São Paulo, principalmente em bacias hidrográficas". Ainda referindo-se ao mapeamento participativo Carpi Junior (2011) reforça a sua importância dizendo que:

$O$ leque de informações que podem ser levantadas acerca de riscos ambientais pela população, que somente o olhar atento e a vivência diária das transformações ambientais podem melhor "denunciar" uma área de estudo, algo que pesquisadores, técnicos e imagens aéreas não são capazes de descrever ou sequer observar (CARPI JUNIOR. 2011 p. 20).

O presente trabalho apresenta em seu cunho metodológico o mapeamento participativo como bem ressaltado anteriormente, onde a intenção de realizar esse método foi identificar os riscos ambientais no bairro Sítio Novo, área rural do município de São Jose do Rio Pardo/SP. Adicionalmente mostrar a importância desse método de pesquisa, que auxilia na identificação de problemas ambientais através da valorização das experiências cognitivas dentro do âmbito da percepção ambiental, vale destacar que a sua principal etapa consiste na realização da reunião pública, onde esta é realizada em etapas para melhor compreensão e efetiva participação da comunidade ali presente.

Primeiramente é realizada uma alfabetização geográfica/cartográfica baseada em Sevá Filho e Carpi Jr. (2001). Nesta alfabetização é fomentada a capacidade de leitura e abstração dos fatos geográficos presentes no mapa, além da familiarização dos participantes com o ambiente no qual estão inseridos, mas que muitas vezes perde significado ao ser representado graficamente.

De acordo com Dagnino (2007) nesta etapa inicial de mapeamento é pedido que os participantes desenhem alguns pontos de referência e áreas mais conhecidas com o intuito de contribuir neste processo de alfabetização. O mesmo autor ainda afirma que: "feito esse procedimento, pode dar início ao mapeamento participativo com a população participante, valorizando a sua percepção".

Cabe considerar que é de suma importância que todo o material necessário para realização da reunião pública esteja pronto com antecedência para que a reunião seja realizada, são eles: mapas base, legendas, folhas para copiar os relatos da população, lápis colorido e também o convite para entregar a população 
que irá participar com data e horário que seja mais viável para os participantes. Feito isso, no dia da reunião, logo em princípio deve ser apresentado para a população participante, a importância de sua presença, os objetivos do trabalho e suas funcionalidades, bem como fazer uma explanação de bases cartográficas e da legenda base que vai ser entregue, onde a mesma pode ser adaptada de acordo com os pontos destacados pela população participante. É entregue um mapa básico para que os participantes possam apontar seus principais problemas, levando em consideração o mapa mental que os mesmos dispõem, devido ao seu convívio com o seu lugar, na figura 2 temos um exemplo da legenda base utilizadas nas reuniões públicas.

Considera relevante ressaltar que nem todas as informações destacadas pelos moradores são possíveis mapear, sendo assim, devem ser colocadas por escrito pelo mediador do grupo.

Figura 2: Legenda base utilizada em reuniões de mapeamento participativo

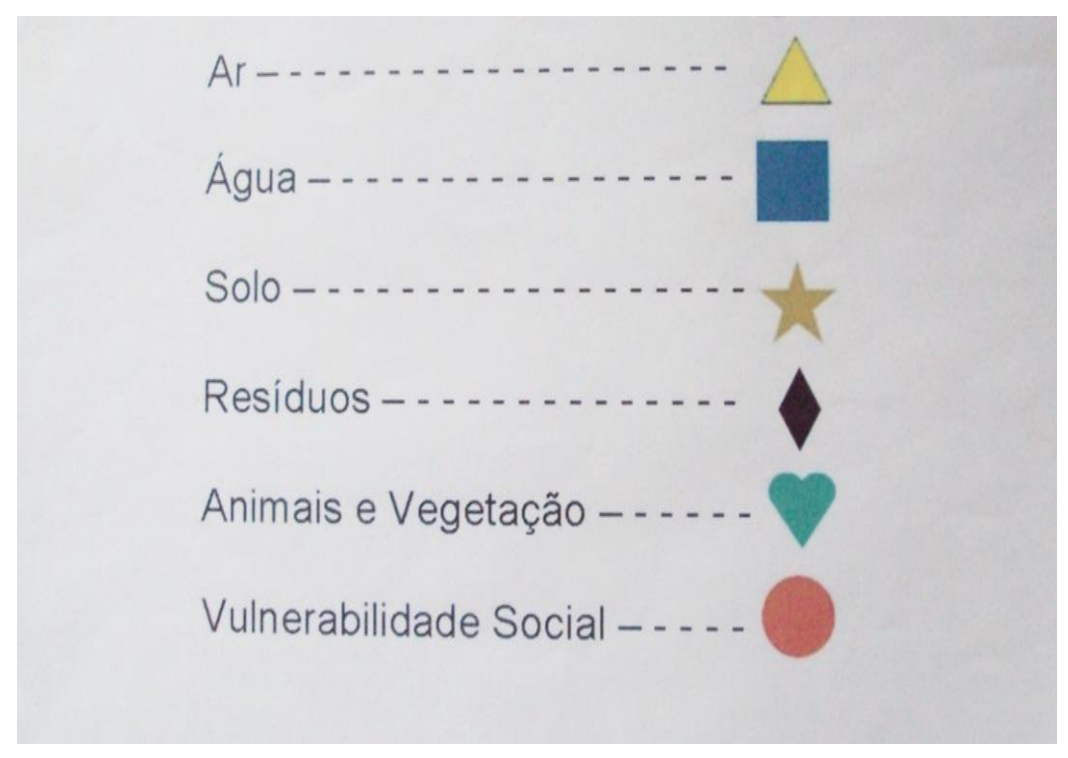

Fonte: CARPI JUNIOR et al., 2005.

Foram aplicados questionários individualmente àqueles que participavam da reunião, apesar de tal ação não ter ocorrido em pesquisas anteriores, estuda-se a relação entre pertencimento e percepção, no projeto de mestrado de Amanda Silva. 
A aplicação de questionários é importante, pois é possível identificar e conhecer o perfil daqueles que participaram da reunião pública, para uma análise mais complexa entre a subjetividade deles e sua relação com o meio em que vivem.

\section{RESULTADOS E DISCUSSÕES}

Na primeira reunião ${ }^{4}$ realizada na Escola Municipal de Ensino Básico Sítio Novo em São José do Rio Pardo/SP, no dia 03 de fevereiro de 2015, se efetuou as etapas metodológicas apontadas anteriormente onde foi levantada uma gama de informações com a população que esteve presente, entre os participantes marcaram presença a comunidade local, entre pais de alunos e agricultores, professores da escola totalizando cerca de 20 pessoas. As pessoas que participaram da reunião foram divididas em dois grupos denominados de grupo A e B, para melhor aplicabilidade do mapeamento, conforme consta nas figuras 03 e 04 abaixo:

\section{Figura 3 - Grupo A em debate}

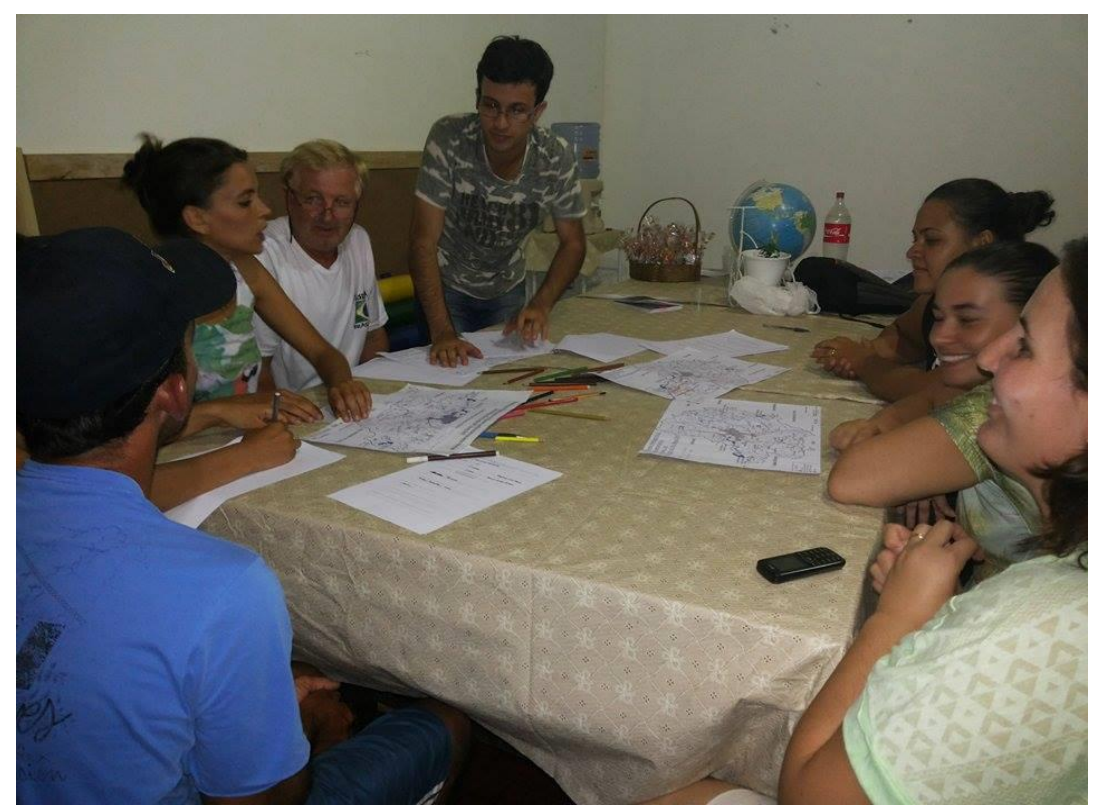

Fonte: AMANDA CRISTINA ALVES SILVA, 2015.

\footnotetext{
${ }^{4}$ Entre as pessoas que estiveram presente na reunião pública de mapeamento participativo no bairro rural Sitio Novo no munícipio de São José do Rio Parto/SP, cabe ressaltar a coordenadora do projeto "escolas do campo", Renata Dalbon que incentiva a prática de valores culturais camponeses nas escolas do município, Amanda Silva mestranda em Geografia pela UNESP de Rio Claro, idealizadora do projeto, juntamente com seu orientador, o pesquisador da Unicamp Salvador Carpi Junior, bem como, a Flavia Darre doutoranda em Ciências Ambientais pela UFSCAR na condição de estagiária e Jeovanes Lisboa da UPE Campus Garanhuns, também estagiário em Metodologias Participativas e Analise Ambiental.
} 
No grupo A, formado quase que em sua totalidade por moradores locais, principalmente mães de alunos, destacam uma série de informações relacionadas à reciclagem de materiais, que já realizada no município, o que é um ponto positivo. Eles têm muito cuidado com o lixo, o separam adequadamente, no entanto não conseguem reciclar tudo, e no bairro não há coleta seletiva, sendo assim a queima desse resíduo acaba ocorrendo, pois nem todos os moradores têm acesso aos locais de coleta.

O rio Verdinho que perpassa esse bairro está poluído, causando mau cheiro para os moradores que o circundam. Outro fator preocupante são as grandes queimadas de cana de açúcar nas propriedades. Foram apontados também vários problemas referentes às estradas não pavimentadas, estas estão sempre com deformidades, assim, os transportes escolares não conseguem levar os alunos para a escola, em outros trechos há falta de lombadas ou sinalização, com isso, muitos caminhões passam em alta velocidade, correndo o risco de haver acidentes, como também fazendo uma grande poeira, prejudicando a saúde de crianças.

Os moradores afirmam que há falta de segurança no local, pois não tem policiamento, culminando em casos de roubos. Os moradores destacaram também a falta de um posto de saúde familiar, e de profissionais da saúde atendendo em suas residências.

Outro ponto que também foi ressaltado refere-se à falta de investimento na produção rural por órgãos pertinentes, o que acarreta a falta de condições de trabalho no campo, levando muitos a irem à cidade em busca de melhores salários.

Os moradores estão enfrentando problemas também com a falta de água, fato esse que se intensificou no ano de 2014 e está se estendendo por 2015 também. Há a diminuição do volume d'água, mesmo todos apresentando reservatório em suas casas.

$\mathrm{Na}$ imagem 04 abaixo apresenta-se os participantes do grupo $\mathrm{B}$ nos principais pontos destacados por eles, algumas coisas são semelhantes ao que foi apontado no grupo A, mas também há vários pontos de importância ímpar para o trabalho, mostrando as diferentes percepções dos participantes. 
Figura 4 - Grupo B em debate

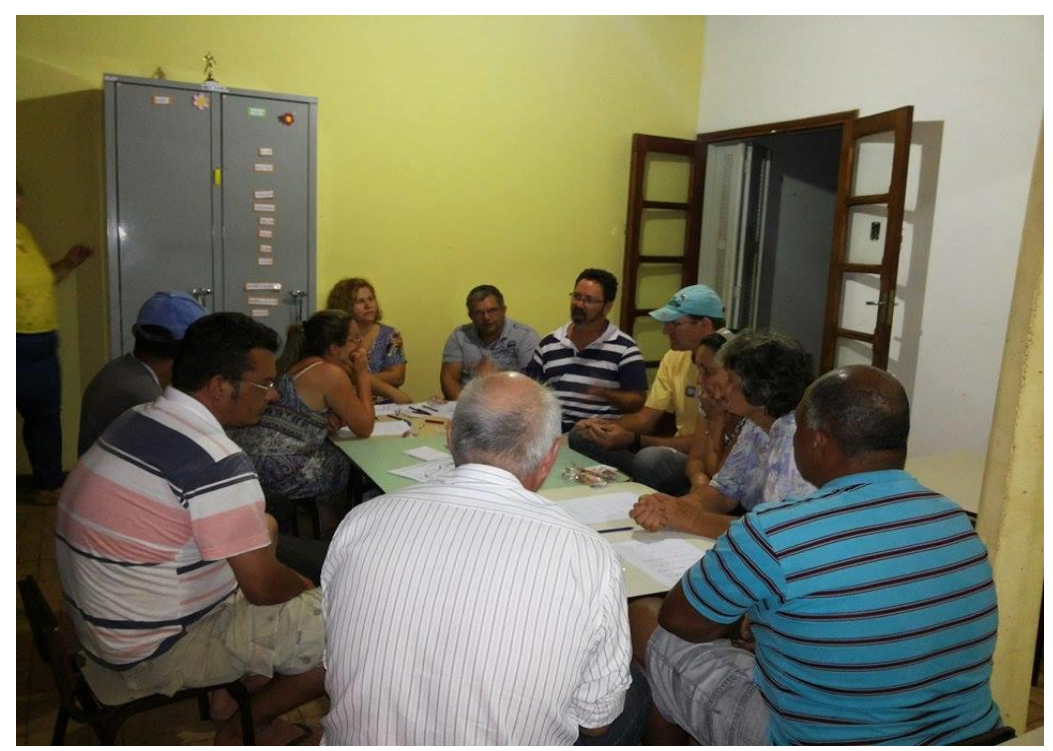

Fonte: AMANDA CRISTINA ALVES SILVA, 2015.

Em consonância com o grupo A, o grupo B destacou que um projeto de asfaltamento é uma necessidade. Tem-se também a presença de locais onde há queimadas acidentais e/ou criminosas principalmente no outono e inverno, que é intensificado pela falta de chuvas nessas estações.

Cabe destacar também um ponto positivo referente à construção de um posto de bombeiros há (cerca de dois anos), que ampliou a sensação de segurança aos arredores de suas instalações.

Há falta de mata ciliar nas margens e nascentes dos rios, como também em açudes, o que é considerado um fator preocupante, como a poluição dos rios próximos com a elevação do número de casos de micose no Rio Verdinho e Rio Verde.

Quanto à falta de manutenção das estradas, tal grupo menciona a dificuldade de acesso por ambulâncias e até mesmo do corpo de bombeiros.

Um ponto preocupante refere-se à falta de conservação do solo, com ocorrência de erosão laminar.

A estação de coleta de embalagem de agrotóxicos para reciclagem é considerada um ponto positivo, contudo não abrange todo $O$ bairro rural que é extenso. Os participantes do grupo $B$ também corroboram com os do grupo A no seguinte aspecto: os assaltos esporádicos e a falta de policiamento no bairro.

O grupo B ainda chama atenção para o seguinte ponto: eles ressaltaram que 
há um excesso de capivaras no bairro inclusive prejudicando a lavoura, outro aspecto que chamou a atenção dos moradores refere-se ao aumento de passarinho e outras aves, tais como, Assum Preto, Canário da Terra, Maritacas e há um aumento também de quatis e saguis, o que provavelmente está relacionado ao crescimento do número de locais preservados, com vegetação nativa ou de reflorestamento.

Depois de todas essas informações destacadas pelos moradores foi produzido um mapa com todos os pontos, na imagem 05 abaixo tem o mapa parcial com essas informações, tanto do que foi ressaltado no Sítio Novo como também do que já foi trabalhado no bairro Água Fria (realizada em 2014) e em outras reuniões.

Figura 5: Mapa de riscos ambientais nos bairros Água Fria e Sítio Novo. Mapeamento de Riscos Ambientais - São José do Rio Pardo / SP Área Rural Sul
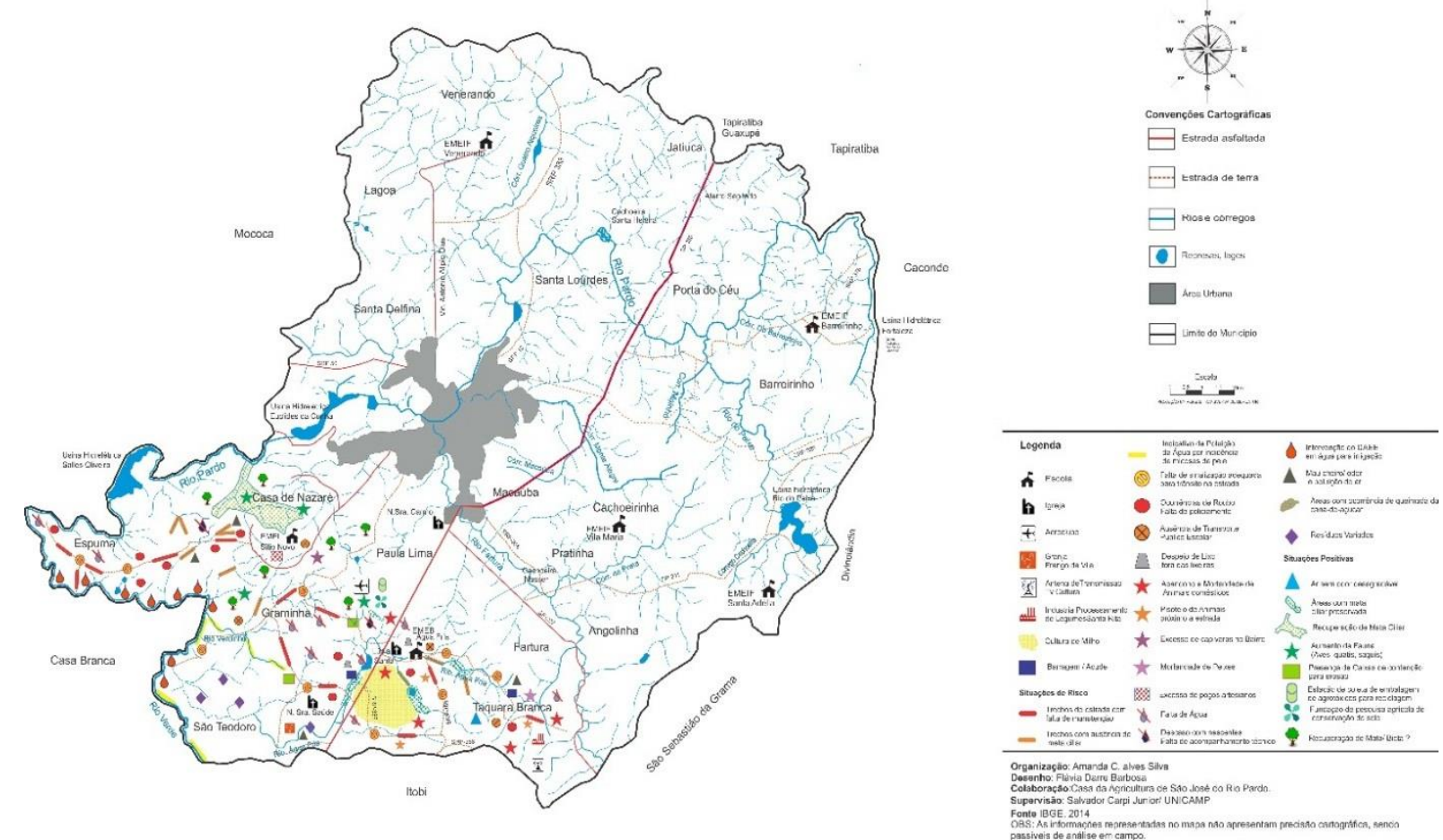

Fonte: Organização Amanda Cristina Alves Silva, 2015.

No mapa acima apresenta os variados pontos destacados pela população como podem ser diferenciados na legenda ao lado, os quais vão dos riscos ambientais aos sociais. 


\section{CONSIDERAÇÕES FINAIS}

Ao se apontar riscos ambientais no bairro rural Sítio Novo, fica claro que as ações capazes de incluir conhecimento científico e empírico em um método de cunho participativo só se concretiza ao considerar o meio em que a sociedade se apresenta e assim estabelece condições de se reproduzir, enquanto moradores de um lugar com disponibilidades de recursos naturais finitos, apoiando-se, portanto na sustentabilidade como forma de garantir perpetuação das condições ambientais saudáveis e qualidade de vida.

O intuito do trabalho fora abordar um método de maior expressividade in loco que é a confecção dos mapas pela comunidade, abrangendo conhecimento e observação de áreas previamente selecionadas onde o mapeamento ambiental participativo é a principal finalidade, onde a mesma percorre diferentes vertentes, tanto científicas quanto empíricas, incluindo estudos de percepção da área rural de São José do Rio Pardo, que conhece e convive com as adversidades presentes no município. Contudo o estudo necessita de diferentes aportes metodológicos tais como trabalhos de campo para melhor precisão dos dados gerados.

A reunião realizada visou identificar e relacionar as potencialidades, os problemas, as oportunidades e as ameaças ali existentes e dar condições para ação local e construção do um plano ambiental participativo.

Os problemas e potencialidades referem-se ao ambiente interno do sistema e as oportunidades e ameaças referem-se ao ambiente externo. Relacionando esses elementos é possível identificar e analisar a realidade existente para transformá-la na realidade desejada.

Foi possível reunir informações levando a uma análise qualitativa que se deu através da percepção e o conhecimento da população envolvida em seu cotidiano com as situações de risco ambiental, principalmente com os problemas ligados à água, ao solo e proteção da vegetação natural, culminando com a produção do mapa de identificação dos riscos ambientais. 


\section{REFERÊNCIAS BIBLIOGRÁFICAS}

Autor: Folharini, S., 2012.

CARPI JR, Salvador. Processos erosivos, riscos ambientais e recursos hídricos na Bacia do Rio Mogi-Guaçu. Tese de Doutorado em Geociências e Meio Ambiente. Rio Claro: IGCE/UNESP, 2001 188 p. Orientações: Prof. Archimedes Perez Filho.

CARPI JR, Salvador; PEREZ Fo, Archimedes. Participação popular no mapeamento de riscos ambientais em bacias hidrográficas. Anais do X Simpósio Brasileiro de Geografia Física Aplicada, Rio de janeiro, nov. 2003.

; Riscos ambientais na Bacia do Rio Mogi-Guaçu: proposta metodológica. Geografia, Rio Claro, v. 30, n. 2, p. 347-364. 2005.

CARPI JUNIOR, S. Mapeamento de riscos ambientais e planejamento participativo de bacias hidrográficas: o caso do manancial Rio Santo Anastácio-SP. 2011. 48 f. Relatórios (PósDoutorado em Geografia) - Universidade Estadual Paulista "Júlio de Mesquita filho", Faculdade de Ciências e Tecnologia, Presidente Prudente, 2011. Disponível em: $<$ http://bacias.fct.unesp.br/gadis/DOCUMENTOS/GestaoDasAguas/PosDoc/relatoriopos_docSalvador .pdf>. Acesso em 25 jan. 2014.

CARPI JR, S.; SCALEANTE, O.; PINTO, A.; ABRAHÃO, C.; TOGNOLI, M. (Org.). Levantamento de riscos ambientais na bacia do ribeirão das Anhumas. In: TORRES, R.; COSTA, M.; NOGUEIRA, F.; PEREZ FILHO, A. (Coord.) Recuperação ambiental, participação e poder público: uma experiência em Campinas (FAPESP 01/02952-1). Relatório de atividades da segunda etapa do Projeto de Políticas Públicas. Campinas, 2005. 122 p. (p. 105 -118). Disponível em: $<$ <ttp://www.iac.sp.gov.br/ProjetoAnhumas/pdf/riscos_ambientais_bacia_ribeirao_anhumas.pdf>.

Acesso em: 05 de março de 2015.

DAGNINO, R. de S. Riscos ambientais na bacia hidrográfica do Ribeirão das Pedras, Campinas/São Paulo. 2007. 127 p. Dissertação (Mestrado em Geografia) - Universidade Estadual de Campinas, Instituto de Geociências. Campinas. 2007.

IBGE - Censo Demográfico 2010. Disponível em: <http://www.censo2010.ibge.gov.br/pt/>. Acesso em 20 de dezembro de 2013.

SEVÁ FILHO, A. O. e CARPI JUNIOR, S. Síntese das atividades e resultados dos projetos Riscos Ambientais na Bacia do Rio Mogi-Guaçu. 25p, 2002. Disponível em: $<$ http://www.researchgate.net/profile/Ricardo_Dagnino/publication/233381856_Mapeamento_participa tivo_de_riscos_ambientais_na_Bacia_Hidrogrfica_do_Ribeiro_das_Anhumas_-

_Campinas_SP/links/Ofcfd50b749078f87b000000.pdf>. Acesso em: 25 de janeiro de 2015.

SEVÁ FILHO, A. O. (Org.) Riscos técnicos coletivos ambientais na Região de Campinas.

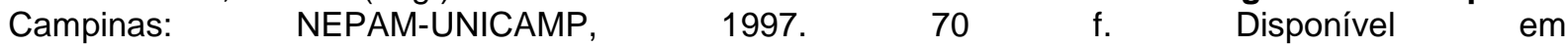
$<\mathrm{http}: / /$ www.ifch.unicamp.br/profseva/riscos_ambientais_Campinas_1997.pdf>. Acesso em: 02 de março 2015.

SILVA, Amanda Cristina Alves. Mapeamento Participativo de Riscos ambientais no bairro rural Água Fria, São José do Rio Pardo. 2015. 67 p. Monografia (Bacharelado em Geografia) Universidade Estadual de Campinas, Instituto de Geociências. Campinas, 2005.

TUAN, Yi - Fu. Topofilia: um estudo da percepção, atitudes e valores do meio ambiente. Tradução de Lívia de Oliveira. Londrina, PR: Eduel, 2012. 